\title{
Left colon as a novel high-risk factor for postoperative recurrence of stage II colon cancer
}

Liming Wang* ${ }^{*}$, Yasumitsu Hirano, Toshimasa Ishii, Hiroka Kondo, Kiyoka Hara, Nao Obara and Shigeki Yamaguchi

\begin{abstract}
Background: It is not clear whether stage II colon and rectal cancer have the same risk factors for recurrence. Thus, the purpose of this study was to identify the risk factors for postoperative recurrence in stage II colorectal cancer.

Patients and methods: We retrospectively analyzed the data of 990 patients who had undergone radical surgery for stage II colorectal cancer. Patients' pathological features and characteristics including age, sex, family history, body mass index, tumor diameter, gross type of tumor, infiltration degree (T3/T4), tumor grade, perineural invasion, vascular invasion, lymphatic invasion, pathologic examination of lymph node number, and preoperative carcinoembryonic assay (CEA) level was compared between patients with and without recurrence. Finally, the prediction of the left and right colons was analyzed.

Results: The mean ages of the colon cancer and rectal cancer patients were 69.5 years and 66.4 years, respectively. In total, 508 (82.1\%) and 285 (76.8\%) patients were treated laparoscopically for colon cancer and rectal cancer, respectively, with median follow-up periods of 42.2 months and 41.8 months, respectively. Forty-four recurrences occurred in both the colon cancer (7.1\%) and rectal cancer (11.9\%) groups. The preoperative serum CEA level and T4 infiltration were significantly higher in recurrent colorectal cancer patients. The postoperative recurrence rate of left colon cancer (descending colon, sigmoid colon) was higher than that of right colon cancer (cecum, ascending colon, transverse colon) (OR 2.191, 95\% Cl 1.091-4.400, $P=0.027$ ). In COX survival factor analysis of colon cancer, the left colon is one of the independent risk factors (risk ratio 5.377, $95 \% \mathrm{Cl} 0.216-0.88, P=0.02)$. In disease-free survival (DFS), the left colon has a relatively poor prognosis $(P=0.05)$. However, in the COX analysis and prognosis analysis of OS, no difference was found between the left colon and the right colon.
\end{abstract}

Conclusion: Preoperative CEA and depth of infiltration (T4) are high-risk factors associated with recurrence and are prognostic factors in stage II colorectal cancer. Left colon is also a risk factor for postoperative recurrence of stage II colon cancer.

Keywords: Colorectal cancer, Carcinoembryonic antigen, Stage II, Left colon cancer

Colorectal cancer (CRC) is one of the most common cancers and a leading cause of cancer-related death in men and women [1]. CRC is also a major cause of death in Japan, being the leading cause in women and the third most common cause in men [2]. The efficacy of adjuvant

\footnotetext{
* Correspondence: wuminami@hotmail.com

Division of Gastroenterological Surgery, Saitama Medical University International Medical Center, Yamane, Hidaka-shi, Saitama 350-1298, Japan
}

chemotherapy for stage II CRC remains controversial, although the benefit of adjuvant chemotherapy for stage III CRC has been established [3-6]. Many studies have reported that rectal cancer differs from colon cancer in etiology, genetics, clinical manifestation, anatomy, and biological characteristics [7], but it is unclear whether stage II colon and rectal cancer have the same risk factors for recurrence. The purpose of this study was to 
identify the risk factors for postoperative recurrence in stage II colorectal cancer.

\section{Patients and methods}

We retrospectively analyzed the clinical data of 990 patients with stage II CRC in the Division of Gastroenterological Surgery of Saitama Medical University from 2007 to 2016. The surgery was considered therapeutic when there was no macroscopic or microscopic residual cancer after surgery. There were 579 men and 411 women, comprising 619 patients with colon cancer and 371 patients with rectal cancer. Patients receiving preoperative treatment or presenting with intestinal obstruction or perforation were excluded from the analysis.

Peripheral blood samples were collected before surgery. The serum CEA level was determined by radioimmunoassay. The CEA level was considered high at $\geq 5 \mathrm{ng} / \mathrm{ml}$. The resected specimens were pathologically classified according to the 7th edition of the Union for International Cancer Control TNM classification of malignant tumors.

Table 1 Clinicopathological parameters in stage II colon and rectal cancer

\begin{tabular}{|c|c|c|c|}
\hline Clinicopathological Parameters & Rectal cancer & Colon cancer & $P$ value \\
\hline Gender (Total n=) & 371 (100.00\%) & $619(100.00 \%)$ & \\
\hline Male & $245(66.04 \%)$ & $334(53.96 \%)$ & \\
\hline Female & $126(33.96 \%)$ & $285(46.04 \%)$ & $<0.01$ \\
\hline Age (year) & $66.4 \pm 0.55$ & $69.5 \pm 0.42$ & $<0.01$ \\
\hline \multicolumn{4}{|l|}{ Post Operation Recurrence } \\
\hline No & $327(88.14 \%)$ & $574(92.73 \%)$ & \\
\hline Yes & $44(11.86 \%)$ & $44(7.11 \%)$ & 0.011 \\
\hline \multicolumn{4}{|l|}{ Open or Laparoscopic } \\
\hline Open & $86(23.18 \%)$ & $113(18.26 \%)$ & \\
\hline Laparoscopic & $285(76.82 \%)$ & $508(82.07 \%)$ & 0.059 \\
\hline \multicolumn{4}{|l|}{ Gross Type } \\
\hline Protruding & $18(4.85 \%)$ & $56(9.05 \%)$ & \\
\hline Ulcerative \& Infiltratie & $353(95.15 \%)$ & $563(90.95 \%)$ & 0.015 \\
\hline Diameter (cm) & $5.44 \pm 0.11$ & $5.24 \pm 0.10$ & 0.105 \\
\hline \multicolumn{4}{|l|}{ Differentiation } \\
\hline Well \& Moderate & $354(95.42 \%)$ & $581(93.86 \%)$ & \\
\hline Poor \& Mucinous & $17(4.58 \%)$ & $38(6.14 \%)$ & 0.37 \\
\hline \multicolumn{4}{|l|}{$\mathrm{T}$} \\
\hline T3 & $329(89.648 \%)$ & $536(87.39 \%)$ & \\
\hline $\mathrm{T} 4$ & $39(10.51 \%)$ & $78(12.60 \%)$ & 0.324 \\
\hline \multicolumn{4}{|l|}{ CEA (ng/mL) } \\
\hline$<5$ & $192(51.75 \%)$ & $400(64.62 \%)$ & \\
\hline$\geq 5$ & $179(48.25 \%)$ & 219 (35.38\%) & $<0.01$ \\
\hline \multicolumn{4}{|l|}{ Number of dissected lymph nodes } \\
\hline$<12$ & $59(15.90 \%)$ & $71(11.47 \%)$ & \\
\hline$\geq 12$ & $312(84.10 \%)$ & $548(88.53 \%)$ & 0.05 \\
\hline \multicolumn{4}{|l|}{ Perineural Invasion } \\
\hline No & $316(85.18 \%)$ & $523(84.49 \%)$ & \\
\hline Yes & $55(14.82 \%)$ & $96(15.51 \%)$ & 0.77 \\
\hline \multicolumn{4}{|l|}{ Vascular Invasion } \\
\hline No & $318(85.71 \%)$ & $263(42.49 \%)$ & \\
\hline Yes & $53(14.29 \%)$ & $356(57.51 \%)$ & $<0.01$ \\
\hline \multicolumn{4}{|l|}{ Infiltration lymphatic vessels } \\
\hline No & $312(84.10 \%)$ & 501 (80.94\%) & \\
\hline Yes & 59 (15.90\%) & $118(19.06 \%)$ & 0.24 \\
\hline
\end{tabular}


Table 2 Clinicopathological parameters for rectal cancer recurrence and non-recurrence

\begin{tabular}{|c|c|c|c|}
\hline Clinicopathological Parameters & Rectal Non-Recurrence & Rectal Recurrence & $P$ value \\
\hline Gender (Total $\mathrm{n}=$ ) & $327(100.00 \%)$ & $44(100.00 \%)$ & \\
\hline Male & $216(66.06 \%)$ & 29 (65.91\%) & \\
\hline Female & 111 (33.94\%) & 15 (34.09\%) & 0.88 \\
\hline Age (year) & $66.35 \pm 1.32$ & $65.7 \pm 0.55$ & 0.30 \\
\hline \multicolumn{4}{|l|}{ Cancer Familly History } \\
\hline None & $140(42.81 \%)$ & $22(50.00 \%)$ & \\
\hline Yes & 187 (57.19\%) & $22(50.00 \%)$ & 0.45 \\
\hline \multicolumn{4}{|l|}{ BMI } \\
\hline$<25$ & 309 (94.50\%) & $34(77.27 \%)$ & \\
\hline$\geq 25$ & $18(5.50 \%)$ & $10(22.73 \%)$ & 0.0001 \\
\hline \multicolumn{4}{|l|}{ Duplicate cancer } \\
\hline None & $298(91.13 \%)$ & $38(86.36 \%)$ & \\
\hline Yes & $29(8.87 \%)$ & $6(13.64 \%)$ & 0.45 \\
\hline \multicolumn{4}{|l|}{ Multiple Cancer } \\
\hline None & 308 (94.19\%) & $38(86.36 \%)$ & \\
\hline Yes & 19 (5.81\%) & $6(13.64 \%)$ & 0.104 \\
\hline \multicolumn{4}{|l|}{ Post Appendectomy } \\
\hline None & $266(81.35 \%)$ & 37 (84.09\%) & \\
\hline Yes & $61(18.65 \%)$ & $7(15.91 \%)$ & 0.81 \\
\hline \multicolumn{4}{|l|}{ Gross Type } \\
\hline Protruding & $20(6.12 \%)$ & $2(4.55 \%)$ & \\
\hline Ulcerative \& Infiltratie & 307 (93.88\%) & $42(95.45 \%)$ & 0.94 \\
\hline Diameter $(\mathrm{cm})$ & $5.42 \pm 0.11$ & $6.00 \pm 0.34$ & 0.045 \\
\hline \multicolumn{4}{|l|}{ Differentiation } \\
\hline Well \& Moderate & $316(96.64 \%)$ & $38(86.36 \%)$ & \\
\hline Poor \& Mucinous & $11(3.36 \%)$ & $6(13.64 \%)$ & 0.007 \\
\hline \multicolumn{4}{|l|}{$\mathrm{T}$} \\
\hline T3 & $298(91.15 \%)$ & $30(68.17 \%)$ & \\
\hline T4 & $29(8.85 \%)$ & $14(31.82 \%)$ & 0.005 \\
\hline \multicolumn{4}{|l|}{ CEA (ng/mL) } \\
\hline$<5$ & 187 (57.19\%) & $14(31.82 \%)$ & \\
\hline$\geq 5$ & $140(42.81 \%)$ & $30(68.18 \%)$ & 0.002 \\
\hline \multicolumn{4}{|l|}{ Number of dissected lymph nodes } \\
\hline$<12$ & $54(16.51 \%)$ & $6(13.64 \%)$ & \\
\hline$\geq 12$ & $273(83.49 \%)$ & $38(86.36 \%)$ & 0.78 \\
\hline Perineural Invasion & & $(0.00 \%)$ & \\
\hline No & 49 (14.98\%) & 37 (84.09\%) & \\
\hline Yes & $278(85.02 \%)$ & $7(15.91 \%)$ & $<0.001$ \\
\hline \multicolumn{4}{|l|}{ Vascular Invasion } \\
\hline No & 118 (36.09\%) & $8(18.18 \%)$ & \\
\hline Yes & 209 (63.91\%) & $36(81.82 \%)$ & 0.028 \\
\hline \multicolumn{4}{|l|}{ Infiltration lymphatic vessels } \\
\hline No & 291 (88.99\%) & $29(65.91 \%)$ & \\
\hline Yes & $36(11.01 \%)$ & 15 (34.09\%) & $<0.001$ \\
\hline
\end{tabular}


Table 3 Clinicopathological parameters for colon cancer recurrence and non-recurrence

\begin{tabular}{|c|c|c|c|}
\hline Clinicopathological Parameters & Colon Non-Recurrence & Colon Recurrence & $P$ value \\
\hline Gender (Total $n=$ ) & $575(100.00 \%)$ & $44(100.00 \%)$ & \\
\hline Male & $309(53.74 \%)$ & $24(54.55 \%)$ & \\
\hline Female & $266(46.26 \%)$ & $20(45.45 \%)$ & 0.95 \\
\hline Age (year) & $69.7 \pm 0.43$ & $70.32 \pm 1.73$ & 0.35 \\
\hline \multicolumn{4}{|l|}{ Cancer Familly History } \\
\hline None & $272(47.30 \%)$ & $19(43.18 \%)$ & \\
\hline Yes & $303(52.70 \%)$ & $25(56.82 \%)$ & 0.71 \\
\hline \multicolumn{4}{|l|}{ BMI } \\
\hline$<25$ & $448(77.91 \%)$ & $36(81.82 \%)$ & \\
\hline$\geq 25$ & $127(22.09 \%)$ & $8(18.18 \%)$ & 0.67 \\
\hline \multicolumn{4}{|l|}{ Duplicate cancer } \\
\hline None & $493(85.74 \%)$ & $40(90.91 \%)$ & \\
\hline Yes & $82(14.26 \%)$ & $4(9.09 \%)$ & 0.46 \\
\hline \multicolumn{4}{|l|}{ Multiple Cancer } \\
\hline None & $543(94.43 \%)$ & $42(95.45 \%)$ & \\
\hline Yes & $32(5.57 \%)$ & $2(4.55 \%)$ & 0.95 \\
\hline \multicolumn{4}{|l|}{ Tumor location } \\
\hline Left colon & $278(48.34 \%)$ & $27(61.37 \%)$ & \\
\hline Right colon & $297(51.65 \%)$ & $17(38.63 \%)$ & 0.09 \\
\hline \multicolumn{4}{|l|}{ Gross Type } \\
\hline Protruding & $51(8.87 \%)$ & $1(2.27 \%)$ & \\
\hline Ulcerative \& Infiltratie & $524(91.13 \%)$ & $43(97.73 \%)$ & 0.21 \\
\hline Diameter (cm) & $5.2 \pm 0.10$ & $5.45 \pm 0.48$ & 0.25 \\
\hline \multicolumn{4}{|l|}{ Differentiation } \\
\hline Well \& Moderate & $527(91.65 \%)$ & 37 (84.09\%) & \\
\hline Poor \& Mucinous & $48(8.35 \%)$ & 7 (15.91\%) & 0.15 \\
\hline \multicolumn{4}{|l|}{$\mathrm{T}$} \\
\hline T3 & $511(88.8 \%)$ & $30(68.18 \%)$ & \\
\hline T4 & $64(11.2 \%)$ & $14(31.82 \%)$ & $<0.0001$ \\
\hline \multicolumn{4}{|l|}{ CEA (ng/mL) } \\
\hline$<5$ & $380(66.09 \%)$ & $20(45.45 \%)$ & \\
\hline$\geq 5$ & 195 (33.91\%) & $24(54.55 \%)$ & 0.009 \\
\hline \multicolumn{4}{|l|}{ Number of dissected lymph nodes } \\
\hline$<12$ & $68(11.83 \%)$ & $4(9.09 \%)$ & \\
\hline$\geq 12$ & $507(88.17 \%)$ & $40(90.91 \%)$ & 0.76 \\
\hline Perineural Invasion & $(0.00 \%)$ & & \\
\hline No & $494(85.91 \%)$ & $40(90.91 \%)$ & \\
\hline Yes & $81(14.09 \%)$ & $4(9.09 \%)$ & 0.48 \\
\hline \multicolumn{4}{|l|}{ Vascular Invasion } \\
\hline No & $250(43.48 \%)$ & $13(29.55 \%)$ & \\
\hline Yes & $325(56.52 \%)$ & $31(70.45 \%)$ & 0.1 \\
\hline \multicolumn{4}{|l|}{ Infiltration lymphatic vessels } \\
\hline No & $469(81.57 \%)$ & $35(79.55 \%)$ & \\
\hline Yes & $106(18.43 \%)$ & $9(20.45 \%)$ & 0.89 \\
\hline
\end{tabular}


Table 4 Correlations between the preoperative CEA levels and the site of recurrence in stage II rectal cancer and colon cancer

\begin{tabular}{|c|c|c|c|c|c|c|}
\hline & \multicolumn{3}{|c|}{ Rectal Cancer CEA ( ng/ml) } & \multicolumn{3}{|c|}{ Colon Cancer CEA ( ng/ml) } \\
\hline & $C E A<5$ & $C E A \geq 5$ & \multirow{2}{*}{$\begin{array}{l}p \text { - } \\
\text { Value }\end{array}$} & CEA $<5$ & $C E A \geq 5$ & \multirow{2}{*}{$\begin{array}{l}p- \\
\text { Value }\end{array}$} \\
\hline & $n=191$ & $n=170$ & & $n=389$ & $n=219$ & \\
\hline \multicolumn{7}{|c|}{ Liver metastasis } \\
\hline Negative & 187 (97.91\%) & 161 (94.71\%) & & 381 (97.94\%) & $209(95.43 \%)$ & \\
\hline Positive & $4(2.09 \%)$ & $9(5.29 \%)$ & 0.10 & $8(2.06 \%)$ & $10(4.57 \%)$ & 0.07 \\
\hline \multicolumn{7}{|c|}{ Lung metastasis } \\
\hline Negative & 187 (97.91\%) & $163(95.88 \%)$ & & $384(98.71 \%)$ & $214(97.72 \%)$ & \\
\hline Positive & $4(2.09 \%)$ & $7(4.12 \%)$ & 0.26 & $5(1.29 \%)$ & $5(2.28 \%)$ & 0.35 \\
\hline \multicolumn{7}{|c|}{ Local recurrence } \\
\hline Negative & 185 (96.08\%) & 157 (92.35\%) & & $384(98.71 \%)$ & $213(97.26 \%)$ & \\
\hline Positive & $6(3.92 \%)$ & $13(7.65 \%)$ & 0.028 & $5(1.29 \%)$ & $6(2.74 \%)$ & 0.96 \\
\hline \multicolumn{7}{|c|}{ Peritoneal dissemination } \\
\hline Negative & $190(99.48 \%)$ & 169 (99.41\%) & & $386(99.23 \%)$ & $213(97.26 \%)$ & \\
\hline Positive & $1(0.52 \%)$ & $1(0.59 \%)$ & 0.93 & $3(0.77 \%)$ & $6(2.74 \%)$ & 0.053 \\
\hline
\end{tabular}

All patients underwent follow up with regular physical and blood examinations, colonoscopy, and computed tomography. All statistical analyses were performed using the SPSS software package version 22.0 for Macintosh (IBM Japan, Tokyo, Japan). The significance of the correlations between the preoperative CEA level and the pathological features was analyzed using the chi-squared test for independence according to each parameter. In order to control for confounding factors, binary logistic regression was used. Wald test was used to evaluate the significance of the association. Survival curves were plotted with the Kaplan-Meier method and analyzed with a log-rank test. $P<0.05$ was considered statistically significant.

\section{Results}

Clinical characteristics of CRCs

As shown in Table 1, a total of 990 CRC patients were included, comprising 371 with rectal cancer and 619 with colon cancer. The mean ages of colon cancer and rectal cancer patients were 69.5 years and 66.4 years, respectively. Of these, $508(82.1 \%)$ of the colon cancer patients and $285(76.8 \%)$ of the rectal cancer patients were treated laparoscopically. The median follow-up periods were 42.2 months for colon cancer and 41.8 months for rectal cancer. Forty-four recurrences occurred in both the colon cancer (7.1\%) and rectal cancer (11.9\%) groups. We observed significant differences between the colon and rectal cancer patients regarding sex, average

Table 5 Correlations between the depth of infiltration and the site of recurrence in stage II rectal cancer and colon cancer

\begin{tabular}{|c|c|c|c|c|c|c|}
\hline & \multicolumn{3}{|l|}{ Rectal Cancer } & \multicolumn{3}{|l|}{ Colon Cancer } \\
\hline & T3 & T4 & \multirow{2}{*}{$\begin{array}{l}p- \\
\text { Value }\end{array}$} & T3 & $\mathrm{T} 4$ & \multirow{2}{*}{$\begin{array}{l}p- \\
\text { Value }\end{array}$} \\
\hline & $n=332$ & $n=39$ & & $n=542$ & $n=77$ & \\
\hline \multicolumn{7}{|c|}{ Liver metastasis } \\
\hline Negative & 320 (96.39\%) & 38 (97.44\%) & & $526(97.05 \%)$ & $74(96.10 \%)$ & \\
\hline Positive & $12(3.61 \%)$ & $1(2.56 \%)$ & 0.735 & $16(2.95 \%)$ & $3(3.90 \%)$ & 0.651 \\
\hline \multicolumn{7}{|c|}{ Lung metastasis } \\
\hline Negative & 325 (97.89\%) & 35 (89.74\%) & & 535 (98.71\%) & $74(96.10 \%)$ & \\
\hline Positive & $7(2.11 \%)$ & $4(10.26 \%)$ & 0.004 & $7(1.29 \%)$ & $3(3.90 \%)$ & 0.089 \\
\hline \multicolumn{7}{|c|}{ Local recurrence } \\
\hline Negative & $318(95.78 \%)$ & $34(87.18 \%)$ & & $534(98.52 \%)$ & $70(90.91 \%)$ & \\
\hline Positive & $14(4.22 \%)$ & $5(12.82 \%)$ & 0.021 & $8(1.48 \%)$ & 7 (9.09\%) & $<0.001$ \\
\hline \multicolumn{7}{|c|}{ Peritoneal dissemination } \\
\hline Negative & 331 (99.70\%) & 38 (97.44\%) & & 538 (99.26\%) & $74(96.10 \%)$ & \\
\hline Positive & 1 (0.30\%) & 1 (2.56\%) & 0.067 & 4 (0.74\%) & 3 (3.90\%) & 0.014 \\
\hline
\end{tabular}


Table 6 Multivariate logistic regression analysis evaluating possible risk factors associated with recurrence

\begin{tabular}{|c|c|c|c|c|c|c|}
\hline & \multicolumn{3}{|l|}{ Rectal Cancer } & \multicolumn{3}{|c|}{ Colon Cancer } \\
\hline & Odds ratio & $95 \% \mathrm{Cl}$ & $p$ & Odds ratio & $95 \% \mathrm{Cl}$ & $p$ \\
\hline Gender & 1.259 & $0.587-2.70$ & 0.554 & 0.879 & $0.453-1.704$ & 0.702 \\
\hline Age, year & 0.983 & $0.953-1.014$ & 0.270 & 1.017 & $0.985-1.050$ & 0.300 \\
\hline T4 vs T3 & 3.867 & $1.547-9.663$ & 0.004 & 3.222 & $1.238-8.390$ & 0.017 \\
\hline CEA (ng/mL) & 1.011 & $1.000-1.021$ & 0.048 & 1.010 & $1.003-1.017$ & 0.004 \\
\hline \multirow[t]{2}{*}{ Tumor location } & \multicolumn{3}{|l|}{$\mathrm{Rb}$ vs $\mathrm{Ra}, \mathrm{RS}$} & \multicolumn{3}{|c|}{ Left colon vs Right colon } \\
\hline & 0.825 & $0.411-1.651$ & 0.589 & 2.191 & 1. $091-4.400$ & 0.027 \\
\hline
\end{tabular}

Tumor location*: Rectal cancer (Rb \& Ra, RS). Ra rectum above the peritoneal reflection, $R b$ rectum below the peritoneal reflection, $R S$ rectosigmoid. Colon cancer: Left colon (Descending colon, sigmoid colon) \& Right colon( Cecum, ascending colon, transverse colon)

age, postoperative recurrence rate, gross type, serum CEA levels, and vascular invasion (all $P<0.05$ ). Other features were not significantly different, including open or laparoscopic methods, differentiation, invasion depth $(\mathrm{T})$, perineural invasion, cancer diameter, and infiltration of lymphatic vessels.

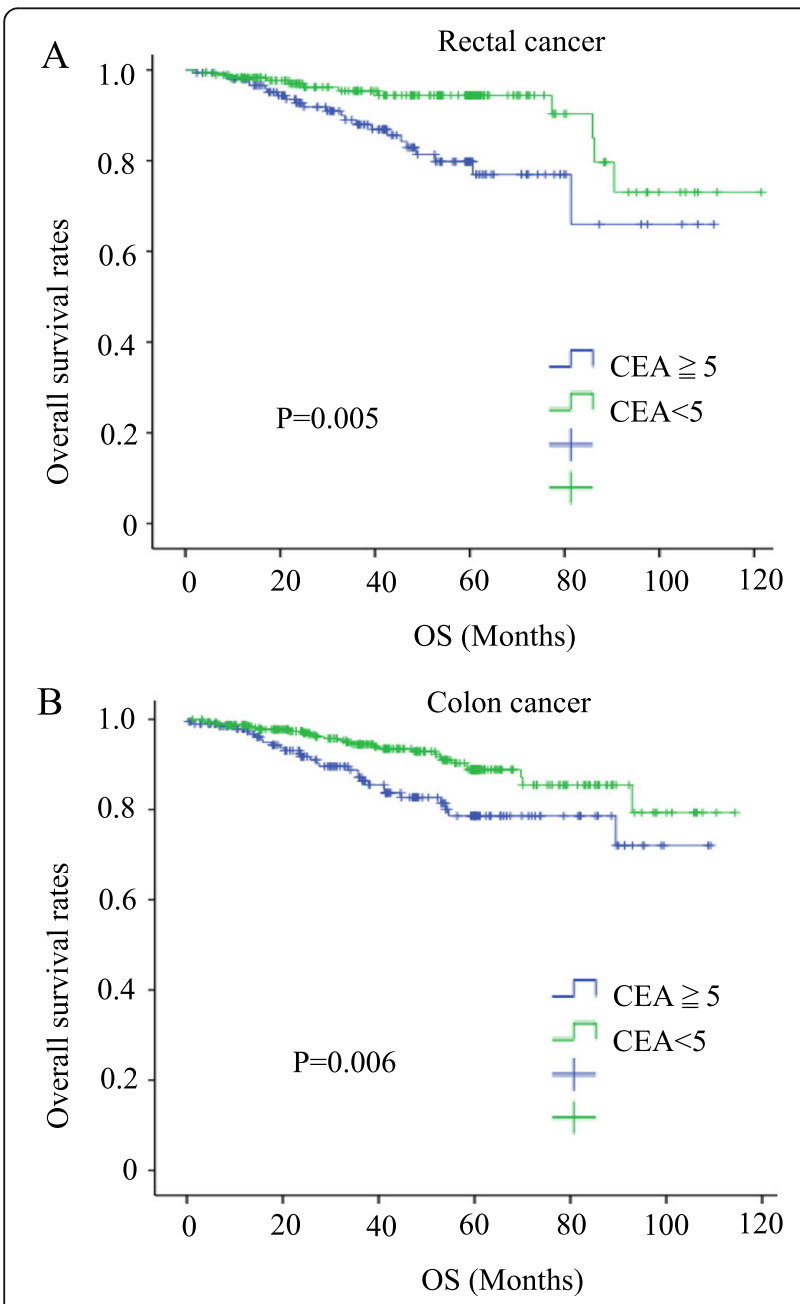

Fig. 1 Survival outcomes for colorectal cancer patients with CEA $\geqq 5$ vs. CEA $<5$

\section{Comparisons of clinicopathological parameters between CRC recurrence and non-recurrence}

Rectal cancer recurrence was associated with a body mass index greater than $25 \mathrm{~kg} / \mathrm{m}^{2}(P=0.0001)$, a larger tumor size $(6.00 \pm 0.34 ; P<0.001)$, advanced T stage $(P<0.005)$, higher serum CEA levels $(P<0.002)$, poor differentiation or mucinous histology $(P<0.007)$, perineural invasion $(P$

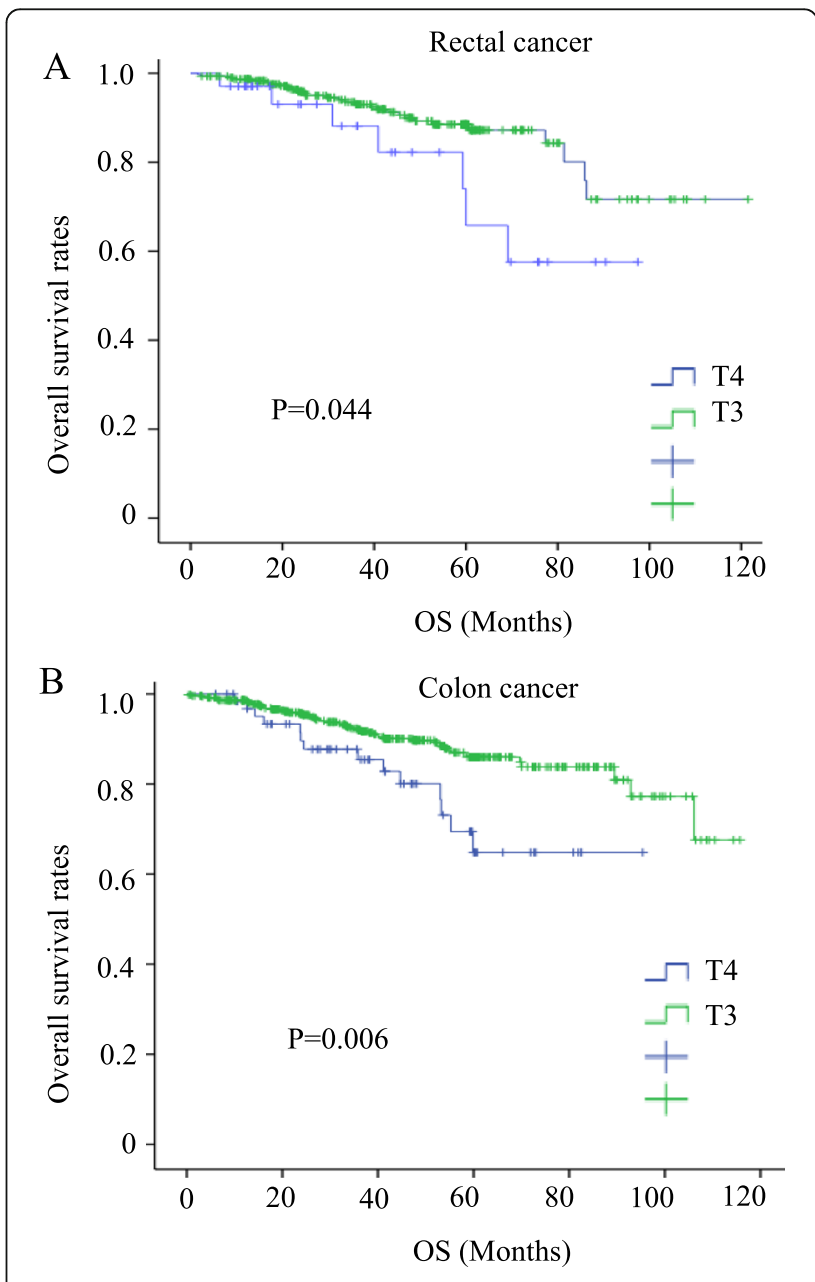

Fig. 2 Survival outcomes for colorectal cancer patients with T3 vs. T4 
$<0.001)$, vascular invasion $(P=0.028)$, and infiltration of lymphatic vessels $(P<0.001)$ (Table 2$)$.

Compared with rectal cancer, colon cancer recurrence was associated with just an advanced $\mathrm{T}$ stage $(P<0.0001)$ and higher serum CEA levels $(P=0.009)$ (Table 3$)$.

\section{Correlations between the preoperative CEA levels and the site of recurrence}

Local recurrences were significantly more common for rectal cancers with a higher CEA level than for those with a lower CEA level $(P<0.05)$. However, there was no significant difference in liver metastasis, lung metastasis, or peritoneal spread between the two groups (Table 4).

Although the patients with higher CEA levels were more likely to develop colon cancer recurrence, there was no significant difference in the site of recurrence (Table 4).
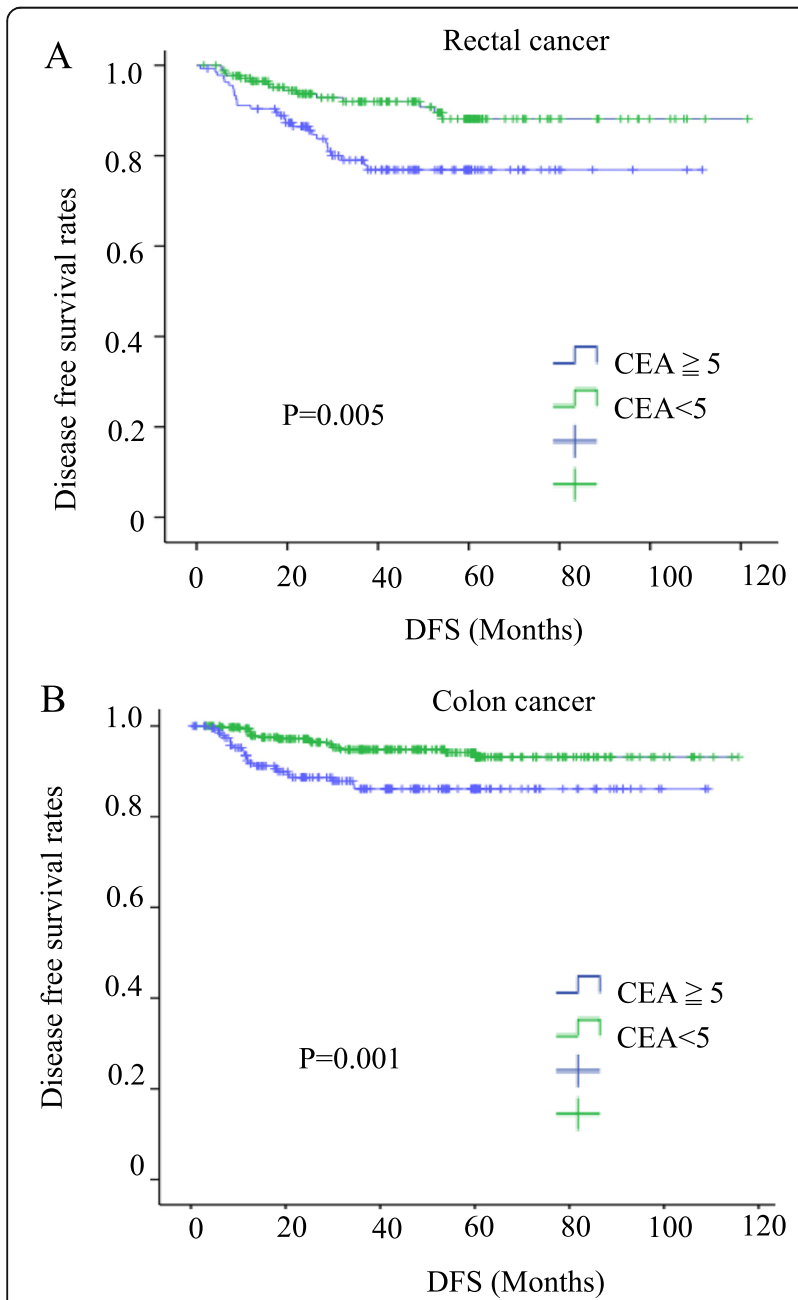

Fig. 3 Disease-free survival for colorectal cancer patients with CEA $\geqq$ 5 vs. CEA $<5$

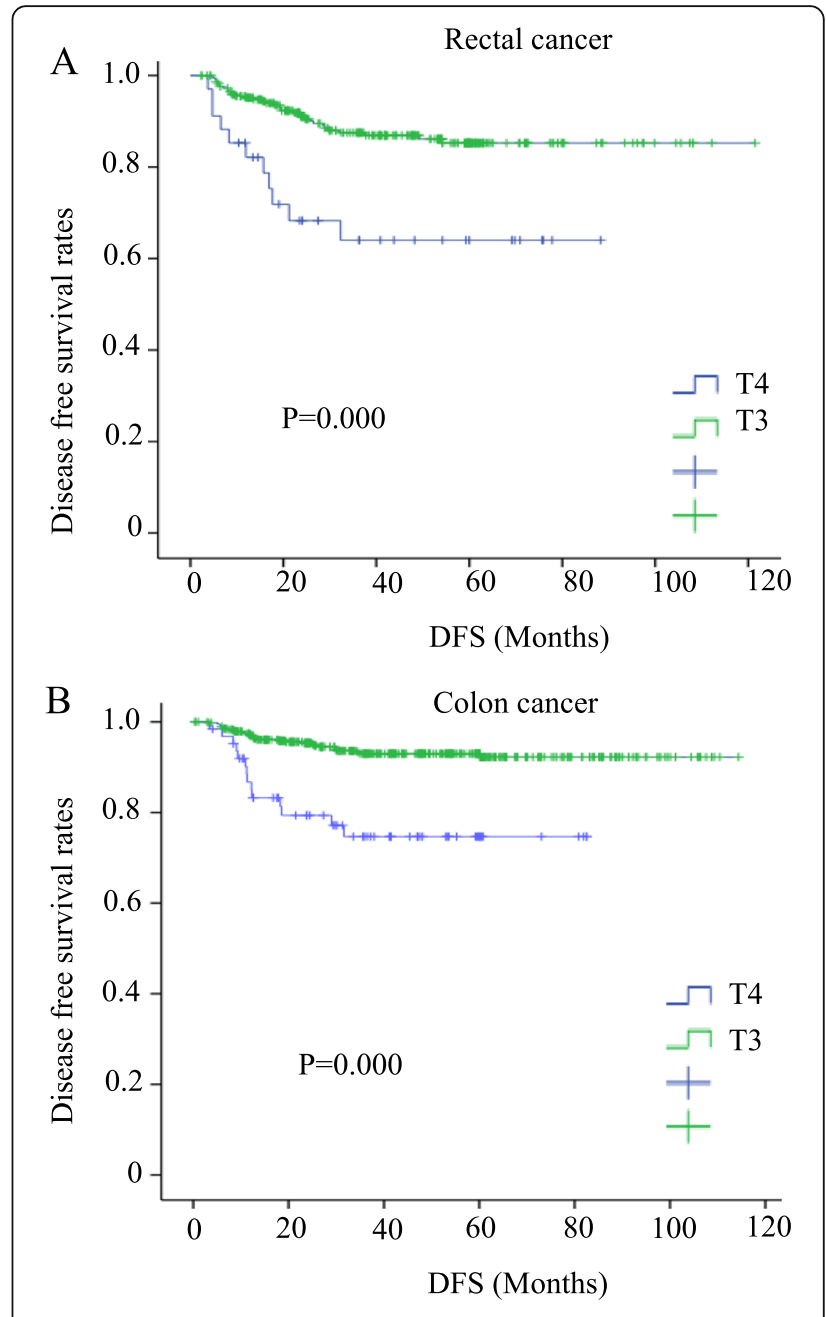

Fig. 4 Disease-free survival for colorectal cancer patients with T3 vs. T4

\section{Correlations between the depth of infiltration and the site of recurrence}

Local recurrences were significantly more common for colorectal cancers with T4 infiltration than for those with T3 infiltration (both $P<0.05$ ) (Table 5). There was a higher rate of lung metastasis recurrence in patients with T4 rectal cancer compared with T3 $(P=0.004)$. In patients with $\mathrm{T} 4$ colon cancer, there was a higher rate of peritoneal metastasis $(P=0.014)$.

In multivariate analysis, a higher CEA level was associated with a higher chance of recurrence of both rectal cancer (odds ratio [OR] 1.011, 95\% confidence interval [95\% CI] 1.00-1.021, $P=0.048$ ) and colon cancer (OR $1.01095 \%$ CI 1.003-1.017, $P=0.004)$. In addition, T4 cancer had a higher chance of recurrence in both rectal cancer (OR 3.867, 95\% CI 1.547-9.663, $P=0.004$ ) and colon cancer (OR 3.222, 95\% CI 1.238-8.390, $P=0.017$ ) (Table 6). In colon cancer, the postoperative recurrence rate of left colon cancer (descending colon, sigmoid 
Table 7 Cox proportional hazard regression model comparing the effects of different parameters on the prognosis of patients with stage II Colon cancer

\begin{tabular}{|c|ccc|ccc|}
\hline & \multicolumn{3}{|c|}{ Disease free survival rates } & \multicolumn{3}{c|}{ Overall survival rates } \\
\cline { 2 - 7 } & Risk ratio & $95 \%$ CI & P-value & Risk ratio & $95 \%$ CI & P-value \\
\hline \multirow{2}{*}{ Left colon vs. Right colon } & 5.377 & $0.216-0.88$ & 0.02 & 0.001 & $0.587-1.734$ & 0.974 \\
CEA (ng/mL) & 3.416 & $1-1.011$ & 0.065 & 0.213 & $0.995-1.008$ & 0.644 \\
MUC,SRC,Poor vs. ADC & 1.126 & $0.212-1.587$ & 0.289 & 4.975 & $0.199-0.901$ & 0.026 \\
Vascular invasion, Yes vs. No & 6.177 & $0.191-0.822$ & 0.013 & 6.294 & $0.267-0.85$ & 0.012 \\
INF b,c vs. INFa & 6.365 & $1.523-28.485$ & 0.012 & 5.228 & $1.288-26.994$ & 0.022 \\
T4 vs T3 & 11.147 & $0.126-0.583$ & 0.001 & 1.444 & $0.291-1.345$ & 0.23 \\
\hline
\end{tabular}

$A D C$ adenocarcinoma, CEA carcinoembryonic antigen, $C$ confidence interval, SRC signet ring cell carcinoma, $H R$ hazard ratio, Poor poor poorly differentiated adenocarcinoma, INF Infiltrating pattern of invasion, INFa Swelling proliferation, INF c Invasive proliferation, INF $b$ between a and c. vs. versus, Left colon(Descending colon, sigmoid colon); Right colon( Cecum, ascending colon, transverse colon)

colon) was higher than that of right colon cancer (cecum, ascending colon, transverse colon) (OR 2.191, 95\% CI 1.091-4.400, $P=0.027)$. However, there was no significant difference between low rectal cancer and upper rectal cancer.
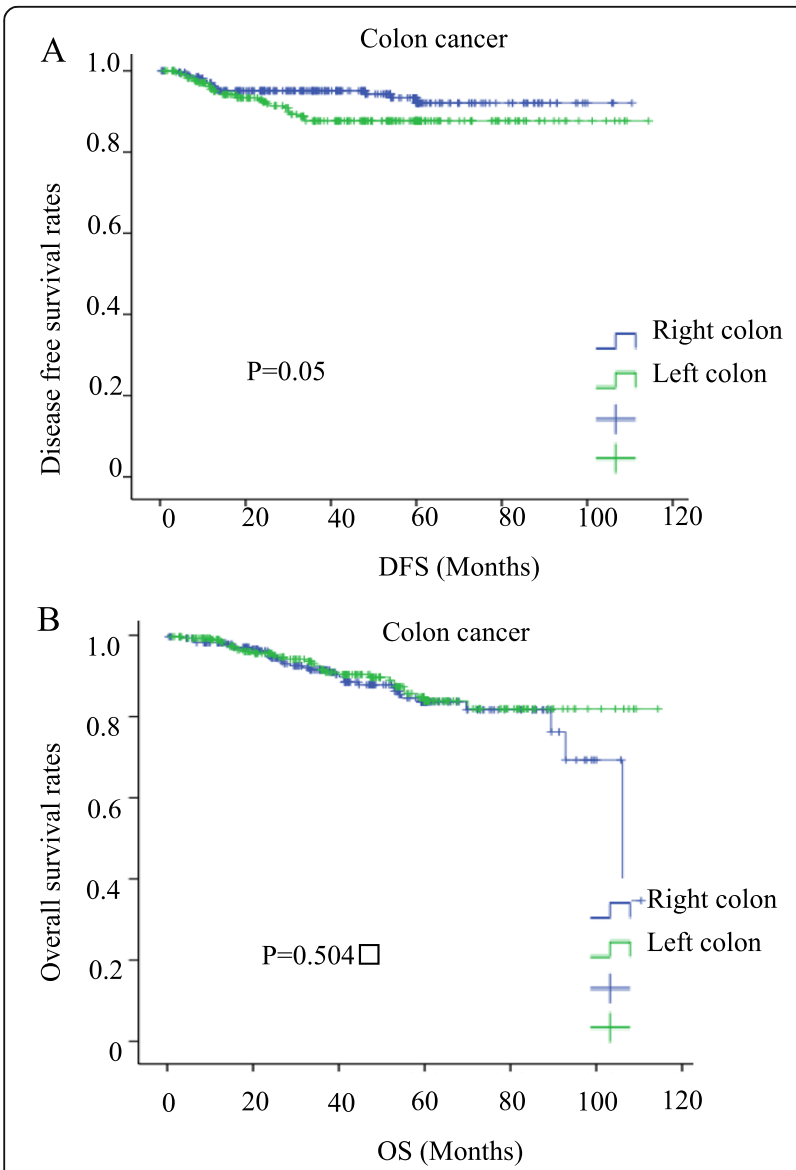

Fig 5 Prognosis of left colon cancer vs. right colon cancer
Correlations of the preoperative CEA levels and depth of infiltration with the survival rate

The overall survival rate was significantly lower in both colon and rectal cancer patients with high levels of CEA and in T4 patients $(P=0.005,0.006,0.0044$, and 0.006 , respectively) (Figs. 1a, b and 2a, b). High levels of serum CEA and T4 reduced the disease-free survival $(P=0.005$, 0.001, 0.000, and 0.000) (Figs. 3a, b and 4a, b).

\section{Prognostic differences between the left colon and the right colon}

To compare the prognosis of histological parameters determined in univariate analysis, Cox's proportional hazard regression model was applied. For DFS, left colon, vascular invasion, infiltrating pattern, and T4 were all shown to be independent risk factors. For OS, signet ring cell carcinoma, mucinous carcinoma, poorly differentiated carcinoma, vascular invasion, infiltrating pattern etc. were shown to be independent risk factors (Table 7). For the DFS Kaplan-Meier survival curve, the left colon also has a relatively poor prognosis. However, in the OS curve, there is no difference between the left colon and the right colon (Fig. 5a, b). There is no statistical difference in the ratio of T4:T3 $(P=0.337)$ and $\mathrm{CEA} \geq 5 \mathrm{ng} / \mathrm{ml}(P=0.32)$ in left colon cancer and right colon cancer (detailed data not shown).

\section{Discussion}

The question of whether colon and rectal cancer should be treated as a single entity or as two separate entities remains controversial [8]. The treatment of stage II CRCs has also been extensively debated [7, 9]. Our findings indicate that these two groups show considerable differences in many clinic-pathological characteristics. Significant differences were seen between the two groups in sex, average age, postoperative recurrence, gross type, surgical procedure (open/laparoscopic), serum CEA level, and vascular invasion. Therefore, our results showed that, in stage II CRC, the characteristics of colon 
cancer and rectal cancer were different, which is why they should be considered two separate entities.

Out of 4,244 primary CRC patients, 990 cases (23.3\%) of stage II CRC were found in our hospital in the past 10 years. In view of the different characteristics of rectal cancer and colon cancer, we independently analyzed their relapse characteristics. The depth of infiltration and level of the preoperative tumor marker CEA were directly related to recurrence in the colon cancer recurrence group compared with the non-recurrence group. This is consistent with the results of another study [10]. However, rectal cancer recurrence is much more complicated. It was not only related to the serum CEA level and depth of infiltration, but also obesity, tumor size, tumor type, and postoperative pathological lymphatic infiltration and perineural invasion. Therefore, CEA level and depth of infiltration are the common factors for the recurrence of the stage II CRC. These results are largely consistent with those of another study that also found that CEA and CA19-9 were factors associated with recurrence $[11,12]$.

We then looked at whether CEA was associated with the site of tumor recurrence. Although CEA is a complex glycoprotein that is the most commonly used tumor marker for CRC, it is highly nonspecific. In colon cancer, we did not find any relationship between CEA and the location of tumor recurrence but it was significantly associated with the local recurrence of rectal cancer. Local recurrence of rectal cancer involves lymph nodes near the sacrum, lymph nodes around the great arteries, and lateral lymph nodes. In this study, the preoperative CEA level and depth of infiltration (T4) were risk factors and prognostic factors for recurrence of stage II colon cancer. The different biological characteristics between rectal cancer and colon cancer lead to diverse recurrence factors and prognostic factors.

We found that the incidence of postoperative recurrence for left colon cancer was higher than that of right, and left colon is one of the independent risk factors of poorer DFS, which was consistent with some reports $[13,14]$. The majority of the literature differs, reporting that there is no difference [15] or that the right colon has a relatively poor prognosis [16-19]. The inclusion of the rectum in the left colon is the biggest difference between these reports. This study also shows that many biological characteristics of the colon and rectum are different. The distinction between the descending colon and the sigmoid colon from the rectum may be more conducive to future treatment.

But more surprisingly, there was no difference in OS between the left colon and the right colon. This may be because the left colon, when compared with the right colon, even though RAS/BRAF are wild-type, has more advantages in the choice of chemotherapy drugs cetuximab or panitumumab [20]. It is important to recognize the limitations of this study. The chemotherapy effect of CRC is closely related to KRAS and BRAF gene mutations or microsatellite instability (MSI) [21]. In future analysis, research on genetic components needs to be strengthened. Second, this study is a single-center retrospective study with a relatively small sample size, and we look forward to future multi-center clinical studies.

\section{Conclusion}

Our results indicate that the preoperative CEA level and depth of infiltration (T4) are high-risk factors associated with recurrence and are prognostic factors in stage II colorectal cancer. Left colon is also a risk factor for the postoperative recurrence of stage II colon cancer, and special attention should be paid during follow-up.

\section{Acknowledgements}

The authors thank the experts at BioMed Proofreading for English copy editing.

\section{Authors' contributions}

LMW and YH drafted the manuscript and provided the original pictures. TI, $\mathrm{HK}, \mathrm{KH}, \mathrm{NO}$, and SY reviewed the manuscript. All authors read and approved the final manuscript.

\section{Funding}

The authors declare that they have no funding.

Availability of data and materials

Not applicable

Ethics approval and consent to participate

All the study participants provided their informed consent. The study design was approved by the Ethics Committee of the Saitama Medical University International Medical Center (Number: 18-274).

\section{Consent for publication}

All patients have agreed to use their personal medical data for research and publication. Please refer to the attached file for details.

\section{Competing interests}

The authors declare that they have no competing interests.

Received: 6 December 2019 Accepted: 17 February 2020

Published online: 11 March 2020

\section{References}

1. Bray F, Ferlay J, Soerjomataram I, Siegel RL, Torre LA, Jemal A. Global cancer statistics 2018: GLOBOCAN estimates of incidence and mortality worldwide for 36 cancers in 185 countries. CA Cancer J Clin. 2018 68(6):394-424.

2. Watanabe $T$, Itabashi M, Shimada $Y$, Tanaka S, Ito $Y$, Ajioka Y, et al. Japanese Society for Cancer of the Colon and Rectum (JSCCR) guidelines 2010 for the treatment of colorectal cancer. Int J Clin Oncol. 2012;17(1):1-29.

3. Akiyoshi T, Kobunai T, Watanabe T. Recent approaches to identifying biomarkers for high-risk stage II colon cancer. Surg Today. 2012;42(11):1037-45.

4. Meyers BM, Cosby R, Quereshy F, Jonker D. Adjuvant systemic chemotherapy for stages II and III colon cancer after complete resection: a clinical practice guideline. Current oncology. 2016;23(6):418-24.

5. Benson AB 3rd, Schrag D, Somerfield MR, Cohen AM, Figueredo AT, Flynn PJ, et al. American Society of Clinical Oncology recommendations on adjuvant chemotherapy for stage II colon cancer. J Clin Oncol. 2004;22(16): 3408-19.

6. Fujita S, Yamamoto S, Akasu T, Moriya Y. Outcome of patients with clinical stage II or III rectal cancer treated without adjuvant radiotherapy. Int J Colorectal Dis. 2008;23(11):1073-9.

7. Frattini M, Balestra D, Suardi S, Oggionni M, Alberici P, Radice $P$, et al. Different genetic features associated with colon and rectal carcinogenesis. 
Clinical cancer research : an official journal of the American Association for Cancer Research. 2004;10(12 Pt 1):4015-21.

8. Boyle P, Zaridze DG, Smans M. Descriptive epidemiology of colorectal cancer. Int J Cancer J Int Cancer. 1985;36(1):9-18.

9. Link KH, Staib L, Kreuser ED, Beger HG. Adjuvant treatment of colon and rectal cancer: impact of chemotherapy, radiotherapy, and immunotherapy on routine postsurgical patient management. Forschungsgruppe Onkologie Gastrointestinaler Tumoren (FOGT). Recent results in cancer research Fortschritte der Krebsforschung Progres dans les recherches sur le cancer. 1996;142:311-52.

10. Petersen VC, Baxter KI, Love SB, Shepherd NA. Identification of objective pathological prognostic determinants and models of prognosis in Dukes' B colon cancer. Gut. 2002;51(1):65-9.

11. Shibutani M, Maeda K, Nagahara H, Ohtani H, Sakurai K, Toyokawa T, et al. Significance of CEA and CA19-9 combination as a prognostic indicator and for recurrence monitoring in patients with stage II colorectal cancer. Anticancer Res. 2014;34(7):3753-8.

12. Betge J, Langner C. Vascular invasion, perineural invasion, and tumour budding: predictors of outcome in colorectal cancer. Acta Gastroenterol Belg. 2011;74(4):516-29.

13. Leijssen LGJ, Dinaux AM, Kunitake H, Bordeianou LG, Berger DL. Pathologic factors are more important than tumor location in long-term survival in colon cancer. Int J Colorectal Dis. 2018;33(6):709-17.

14. Moritani K, Hasegawa H, Okabayashi K, Ishii Y, Endo T, Kitagawa Y. Difference in the recurrence rate between right- and left-sided colon cancer: a 17-year experience at a single institution. Surg Today. 2014;44(9): 1685-91.

15. Qin Q, Yang L, Sun YK, Ying JM, Song Y, Zhang W, et al. Comparison of 627 patients with right- and left-sided colon cancer in China: differences in clinicopathology, recurrence, and survival. Chronic Dis Trans Med. 2017;3(1):51-9.

16. Yang KM, Park IJ, Lee JL, Yoon YS, Kim CW, Lim SB, et al. Does the different locations of colon cancer affect the oncologic outcome? A propensity-score matched analysis. Ann Coloproctol. 2019;35(1):15-23.

17. Lee JM, Han YD, Cho MS, Hur H, Min BS, Lee KY, et al. Impact of tumor sidedness on survival and recurrence patterns in colon cancer patients. Annals of surgical treatment and research. 2019;96(6):296-304.

18. Fukata K, Yuasa N, Takeuchi E, Miyake H, Nagai H, Yoshioka Y, et al. Clinical and prognostic differences between surgically resected right-sided and leftsided colorectal cancer. Surg Today. 2019. https://doi.org/10.1007/s00595019-01889-4.

19. Ben-Aharon I, Goshen-Lago T, Sternschuss M, Morgenstern S, Geva R, Beny $\mathrm{A}$, et al. Sidedness matters: surrogate biomarkers prognosticate colorectal cancer upon anatomic location. The oncologist. 2019;24(8):e696-701.

20. Hashiguchi Y, Muro K, Saito Y, Ito Y, Ajioka Y, Hamaguchi T, et al. Japanese Society for Cancer of the Colon and Rectum (JSCCR) guidelines 2019 for the treatment of colorectal cancer. Int J Clin Oncol. 2020;25(1):1-42.

21. Reynolds IS, Furney SJ, Kay EW, McNamara DA, Prehn JHM, Burke JP. Metaanalysis of the molecular associations of mucinous colorectal cancer. Br J Surg. 2019;106(6):682-91.

\section{Publisher's Note}

Springer Nature remains neutral with regard to jurisdictional claims in published maps and institutional affiliations.

Ready to submit your research? Choose BMC and benefit from:

- fast, convenient online submission

- thorough peer review by experienced researchers in your field

- rapid publication on acceptance

- support for research data, including large and complex data types

- gold Open Access which fosters wider collaboration and increased citations

- maximum visibility for your research: over $100 \mathrm{M}$ website views per year

At BMC, research is always in progress.

Learn more biomedcentral.com/submissions 